Article

\title{
Silane Modification of Crumb Rubber on the Rheological Properties of Rubberized Asphalt
}

\author{
Yunbao Zhang ${ }^{1,2}$, Zhaohui Liu ${ }^{1, *}$ and Juan Peng ${ }^{2}$ \\ 1 School of Traffic and Transportation Engineering, Changsha University of Science \& Technology, \\ No. 960th South Wanjiali Rd., Changsha 410114, China; ybaozhang@126.com \\ 2 Department of Transportation of Hunan Province, No. 1st South Wanjiali Rd., Changsha 410116, China; \\ pj20152334@126.com \\ * Correspondence: zhhliu_csust@163.com
}

Received: 20 October 2019; Accepted: 5 November 2019; Published: 12 November 2019

check for updates

\begin{abstract}
Because there is a lack of studies on rubberized asphalt based on silane coupling agent modification, $\mathrm{KH}-550$ modified crumb rubber and rubberized asphalts incorporating normal rubber and modified rubber were prepared, respectively. The rheological properties of asphalt samples were evaluated by a dynamic shearing rheometer and a bending beam rheometer; then, mechanisms of KH-550 on rubber surface and functional group changes were analyzed by a Brunauer-Emmett-Teller specific surface area measurement and a Fourier transform infrared spectroscopy. The results imply that: (i) rubber surface area rises and chemical reactions accrue between rubber and asphalt; (ii) modified rubber achieves a more stable state within asphalt, which helps to enhance the mechanical properties of asphalt; (iii) modified rubber helps asphalt to dissipate stress so as to resist the formation of cracks and deformation under low temperature conditions.
\end{abstract}

Keywords: KH-550; crumb rubber; rubberized asphalt; rheological; mechanical

\section{Introduction}

Rubberized asphalt (AR) has been developed well in recent years, not only because of the huge consumption of waste tires for manufacturing the crumb rubber (CR), but also the presentation of excellent road performance in the road engineering. According to domestic and overseas research, AR mixture pavement, due to its great high temperature anti-rutting ability, low temperature anti-cracking ability, fatigue resistance ability, and water resistance ability, has been widely popularized and used in many countries [1-6]. However, during real construction of this type of pavement, there is an urgent problem needing to be solved. Researchers and constructors find that CR would gradually segregate from the top asphalt and sink to the bottom during all mixing, transporting, and construction procedures, which finally results in uneven road performance of pavement, such as weeping (extensive oil), rutting, and aging. All these diseases may be accrued at the very beginning and be harmful to the long-term servicing [7-9].

In current studies, constructors and researchers have paid more attention to the adhesion situations between the acid aggregate or the fiber additive and asphalt. Limestone powder and anti-stripping agent are widely used to heighten the bonding state that asphalt tightly grafts on the granite aggregate surface. Besides this, KH-550 (c-ammonia propyl triethoxysilane), a kind of silane coupling agent, is adopted to modify the basalt fiber to enhance the rheological properties of the basalt fiber-reinforced asphalt mucilage [9-12]. The purpose of the above research is to improve the interfacial property between modifier (aggregate, additive) and base material, and in the meantime to acquire a stronger composite with better performance resisting harsh environments. However, there have been few 
studies carried out about crumb rubber surface silane modification and its influences on the macroscopic properties of rubberized asphalt.

At present, mechanisms of KH-550 modification are very clear [9,13-15]. When materials requiring silane modification are mixed with $\mathrm{KH}-550$ solution, $\mathrm{KH}-550$ grafts on the materials' surface through chemical reactions by its organic functional groups. Then, when this silane modified material is mixed with the base material, the inorganic functional groups of KH-550 on the surface of the modified material can dehydrate and condensate with the hydroxyls on the surface of the base material, so that the silane modified material and the base material can be firmly bonded together.

In this study, the most important purpose is to acquire a uniformly "suspended" state of the CR in the asphalt to ensure that modified AR (MAR) has a better road performance. This study adopts $\mathrm{KH}-550$ as the silane coupling agent to prepare the silane modified CR (MCR) and then prepares several asphalt samples incorporating CR and MCR. High and low temperature mechanical properties of asphalt samples are evaluated by rheology tests, and mechanisms of KH-550 on CR and MCR on the asphalt are studied separately. The present research provides an important approach for population and application of CR surface modifications in road construction.

\section{Material and Methodology}

\subsection{Material and Sample Preparation}

\subsubsection{Materials}

70 \# heavy load asphalt was used as the asphalt matrix (AM) to prepare the AR and MAR. Main technical indices are listed in Table 1.

Table 1. Main properties of the asphalt matrix (AM).

\begin{tabular}{|c|c|c|}
\hline \multicolumn{2}{|c|}{ Technical Indices } & Measured Values \\
\hline \multicolumn{2}{|c|}{ Ductility $\left(10{ }^{\circ} \mathrm{C}, 5 \mathrm{~cm} / \mathrm{min}\right)(\mathrm{cm})$} & 34.2 \\
\hline \multicolumn{2}{|c|}{ Penetration $\left(25^{\circ} \mathrm{C}, 100 \mathrm{~g}, 5 \mathrm{~s}\right)(0.1 \mathrm{~mm})$} & 72 \\
\hline \multicolumn{2}{|c|}{ Elasticity recovery $\left(25^{\circ} \mathrm{C}\right)(\%)$} & 89 \\
\hline \multicolumn{2}{|c|}{ Softening point (Ring-ball) $\left({ }^{\circ} \mathrm{C}\right)$} & 55 \\
\hline \multicolumn{2}{|c|}{ Dynamic viscosity $\left(60^{\circ} \mathrm{C}\right)(\mathrm{Pa} \cdot \mathrm{s})$} & 218 \\
\hline \multirow{3}{*}{$163^{\circ} \mathrm{C}$ rolling thin film oven test } & Loss of quality $(\%)$ & -0.285 \\
\hline & Residual ductility $\left(10^{\circ} \mathrm{C}, 5 \mathrm{~cm} / \mathrm{min}\right)(\mathrm{cm})$ & 8.61 \\
\hline & Residual penetration ratio $\left(25^{\circ} \mathrm{C}, 100 \mathrm{~g}, 5 \mathrm{~s}\right)(\%)$ & 69.7 \\
\hline
\end{tabular}

KH-550 (chemical formula: $\mathrm{H}_{2} \mathrm{NCH}_{2} \mathrm{CH}_{2} \mathrm{CH}_{2} \mathrm{Si}\left(\mathrm{OC}_{2} \mathrm{H}_{5}\right)_{3}$; boiling point: $215^{\circ} \mathrm{C}$ ) was adopted, as it can be dissolved in water then appear to have alkaline properties. CR (40 mesh) was adopted to prepare MCR and AR. CR was sieved by water-sieving and then dried, and it was required to meet the screen specifications (see Table 2) before using it.

Table 2. CR (crumb rubber) screen specifications.

\begin{tabular}{cc}
\hline Screen Size (mm) & Pass Rate (\%) \\
\hline 2.00 & 100 \\
1.18 & $65-100$ \\
0.6 & $20-100$ \\
0.3 & $0-45$ \\
0.075 & $0-5$ \\
\hline
\end{tabular}

\subsubsection{MCR Preparation}

A KH-550 mass concentration of $2.0 \% \mathrm{KH}$-solution was prepared firstly by dropping $\mathrm{KH}-550$ into an ethanol solution with a 3:7 water-to-ethanol ratio and agitating this mixture for at least $20 \mathrm{~min}$. 
Then, CR was blended into the above solution and the mixture was agitated for at least $30 \mathrm{~min}$. Lastly, MCR was acquired through the filtering out, washing, and drying processes and it was required to meet the screen specifications before use.

\subsubsection{Asphalt Sample Preparation}

AM was the controlling group and surplus AM was used to prepare AR and MAR. AM needed to be heated at $175^{\circ} \mathrm{C}$ for $1 \mathrm{~h}$ and then $25 \%$ mass content $\mathrm{CR}$ was blended into it. At the same time, the mixture was agitated with a high-speed shear apparatus at no less than $4000 \mathrm{r} / \mathrm{min}$ and at $175^{\circ} \mathrm{C}$ for about $1 \mathrm{~h}$. Then, the above mixture was stored in a $175^{\circ} \mathrm{C}$ oven for at least another $20 \mathrm{~min}$. Finally, AR was gained. The MAR sample was also prepared in the same way. The main technical indices of AR and MAR are displayed in Table 3.

Table 3. Main technical indices of rubberized asphalt (AR) and modified AR (MAR).

\begin{tabular}{ccc}
\hline Technical Indices & AR & MAR \\
\hline Ductility $\left(5^{\circ} \mathrm{C}, 50 \mathrm{~mm} / \mathrm{min}\right)(\mathrm{mm})$ & 105 & 118 \\
Penetration $\left(25^{\circ} \mathrm{C}, 100 \mathrm{~g}, 5 \mathrm{~s}\right)(0.1 \mathrm{~mm})$ & 54.3 & 39.7 \\
Softening point $\left(\right.$ Ring-ball $\left({ }^{\circ} \mathrm{C}\right)$ & 75 & 82 \\
Dynamic viscosity $\left(60^{\circ} \mathrm{C}\right)(\mathrm{Pa} \cdot \mathrm{s})$ & 817 & 1749 \\
\hline
\end{tabular}

\subsection{Experimental Methodology}

\subsubsection{High Temperature Stability}

The dynamic shearing rheometer (DSR) temperature scanning test was used to evaluate the high temperature stability of AM, AR, and MAR. Complex modulus $G^{*}$ and damping factor $\tan (\delta)$ were used as two main indices to determine the changes in anti-rutting ability under increasing temperatures. $G^{*}$ shows the ability of asphalt to resist stress under repeating actions. A bigger $G^{*}$ and a smaller tan $(\delta)$ always mean a greater high temperature performance of asphalt. Rutting factor $G^{*} / \sin (\delta)$ directly reflects the deformation resistance of asphalt. Test conditions were as listed: (a) DSR used $25 \mathrm{~mm}$ parallel plates and maintained a $1 \mathrm{~mm}$ distance between two plates; (b) test temperature was in the range of $50-80^{\circ} \mathrm{C}$; (c) angular frequency was set as $10 \mathrm{rad} / \mathrm{s}$; (d) amplitude was $12 \%$. Lastly, $\mathrm{G}^{*} / \mathrm{sin}(\delta)$ were also calculated at $58^{\circ} \mathrm{C}, 64^{\circ} \mathrm{C}, 70^{\circ} \mathrm{C}$, and $76^{\circ} \mathrm{C}$.

\subsubsection{Low Temperature Performance}

The bending beam rheometer (BBR) test was adopted to evaluate cracking and deformation resistance under low temperature conditions. Stiffness modulus $S$ and its changing rate $m$ are two main results which represent flexibility and stress relaxation ability of asphalt, respectively. If asphalt has a small $S$ and a big $m$, it always has a better low temperature anti-cracking property. Test temperatures were set as $-24{ }^{\circ} \mathrm{C}$ and $-12{ }^{\circ} \mathrm{C}$. When the test constant load was applied on asphalt sample for $60 \mathrm{~s}$, the values of $S$ and $m$ were captured as the effective result values of the test.

\subsubsection{Rubber Surface Property}

The Brunauer-Emmett-Teller (BET) test plays an important role in studying the properties of particles, especially the specific surface area, pore volume, pore size distribution, and nitrogen adsorption-desorption curve [16,17]. In this article, silane coupling agent was grafted on the CR surface through chemical reactions, which led to change the surface property of CR. This study used the BET test to measure the specific surface areas of CR and MCR to evaluate the influences caused by $\mathrm{KH}-550$. Before doing the experiment, $\mathrm{CR}$ and MCR were chilled after vacuum drying for $2 \mathrm{~h}$ at $103^{\circ} \mathrm{C}$. The adsorption medium was $\mathrm{N}_{2}$. 


\subsubsection{Asphalt Functional Group}

Changes in chemical composition or functional group in asphalt can be reflected intuitively by Fourier transform infrared spectroscopy (FTIR) and the influence of silane coupling agent (SCA) on asphalt could be better explained by the change trend in FTIR curve. The FTIR discussion region ranges from the fingerprint region (lower than $1400 \mathrm{~cm}^{-1}$ ) to $4000 \mathrm{~cm}^{-1}$. The photographic plate was $\mathrm{KBr}$ and scanning time was set as 120 times.

\section{Experimental Result and Discussion}

\subsection{High Temperature Stability}

The high temperature stability performance of asphalt mainly shows that it still has the ability to resist permanent deformation under the repeated shear at high temperatures, and the change of viscoelastic composition is relatively stable $[18,19]$. The following content will be analyzed from the complex modulus and damping factor of asphalt and their changing trends are displayed in Figure 1 and Table 4.

Table 4. DSR temperature scanning test results.

\begin{tabular}{|c|c|c|c|c|c|c|c|c|c|c|c|}
\hline \multicolumn{4}{|c|}{$\mathrm{AM}$} & \multicolumn{4}{|c|}{ AR } & \multicolumn{4}{|c|}{ MAR } \\
\hline Temp $\left({ }^{\circ} \mathrm{C}\right)$ & $G^{*}(\mathrm{kPa})$ & $\delta\left(^{\circ}\right)$ & $\tan (\delta)$ & Temp $\left({ }^{\circ} \mathrm{C}\right)$ & $G^{*}(\mathrm{kPa})$ & $\delta\left(^{\circ}\right)$ & $\tan (\delta)$ & Temp $\left({ }^{\circ} \mathrm{C}\right)$ & $G^{*}(\mathrm{kPa})$ & $\delta\left(^{\circ}\right)$ & $\tan (\delta)$ \\
\hline 50.2 & 7.02 & 85.12 & 11.7 & 50.6 & 36.8 & 57.99 & 1.6 & 50 & 46.1 & 55.59 & 1.46 \\
\hline 50.3 & 6.19 & 85.53 & 12.8 & 51.3 & 34 & 58.78 & 1.65 & 50.5 & 44.2 & 55.95 & 1.48 \\
\hline 50.7 & 5.17 & 85.92 & 14 & 52 & 31.3 & 59.53 & 1.7 & 51.1 & 41.1 & 56.48 & 1.51 \\
\hline 51.5 & 4.22 & 86.29 & 15.4 & 52.8 & 28.7 & 60.39 & 1.76 & 52 & 37.4 & 57.17 & 1.55 \\
\hline 52.3 & 3.6 & 86.55 & 16.6 & 53.6 & 26.3 & 61.21 & 1.82 & 53 & 33.4 & 57.99 & 1.6 \\
\hline 53.3 & 3.04 & 86.82 & 18 & 54.5 & 24 & 61.99 & 1.88 & 54.1 & 29.6 & 58.78 & 1.65 \\
\hline 54.2 & 2.58 & 87.07 & 19.5 & 55.3 & 21.8 & 62.85 & 1.95 & 54.9 & 27.1 & 59.39 & 1.69 \\
\hline 55 & 2.23 & 87.28 & 21 & 56.2 & 19.8 & 63.66 & 2.02 & 55.6 & 24.9 & 59.97 & 1.73 \\
\hline 56 & 1.95 & 87.46 & 22.5 & 57.1 & 17.9 & 64.54 & 2.1 & 56.4 & 22.7 & 60.67 & 1.78 \\
\hline 57 & 1.71 & 87.64 & 24.2 & 58 & 16.1 & 65.46 & 2.19 & 57.3 & 20.7 & 61.35 & 1.83 \\
\hline 58 & 1.51 & 87.78 & 25.8 & 59 & 14.5 & 66.41 & 2.29 & 58.1 & 18.9 & 61.99 & 1.88 \\
\hline 59.1 & 1.34 & 87.93 & 27.6 & 60 & 13 & 67.30 & 2.39 & 59 & 17.1 & 62.73 & 1.94 \\
\hline 60.2 & 1.19 & 88.05 & 29.3 & 61 & 11.6 & 68.20 & 2.5 & 60.1 & 15.1 & 63.55 & 2.01 \\
\hline 61.3 & 1.06 & 88.17 & 31.3 & 61.9 & 10.4 & 69.11 & 2.62 & 61.4 & 13.1 & 64.43 & 2.09 \\
\hline 62.3 & 0.949 & 88.28 & 33.3 & 62.9 & 9.3 & 70.02 & 2.75 & 62.7 & 11.5 & 65.36 & 2.18 \\
\hline 63.3 & 0.843 & 88.39 & 35.6 & 63.9 & 8.31 & 70.85 & 2.88 & 63.7 & 10.4 & 66.13 & 2.26 \\
\hline 64.3 & 0.751 & 88.49 & 37.8 & 65 & 7.43 & 71.74 & 3.03 & 64.7 & 9.32 & 66.86 & 2.34 \\
\hline 65.4 & 0.667 & 88.58 & 40.4 & 66 & 6.63 & 72.54 & 3.18 & 65.8 & 8.37 & 67.55 & 2.42 \\
\hline 66.5 & 0.585 & 88.67 & 42.9 & 67 & 5.93 & 73.38 & 3.35 & 66.8 & 7.51 & 68.36 & 2.52 \\
\hline 67.5 & 0.516 & 88.75 & 45.7 & 68 & 5.29 & 74.18 & 3.53 & 67.9 & 6.72 & 69.04 & 2.61 \\
\hline 68.6 & 0.46 & 88.80 & 47.5 & 69 & 4.73 & 74.92 & 3.71 & 69 & 6.03 & 69.68 & 2.7 \\
\hline 69.8 & 0.412 & 88.85 & 49.8 & 70.1 & 4.22 & 75.65 & 3.91 & 70.1 & 5.37 & 70.28 & 2.79 \\
\hline 70.9 & 0.37 & 88.88 & 51.3 & 71.2 & 3.77 & 76.33 & 4.11 & 71.2 & 4.8 & 70.85 & 2.88 \\
\hline 72 & 0.333 & 88.91 & 52.3 & 72.2 & 3.37 & 76.97 & 4.32 & 72.4 & 4.28 & 71.45 & 2.98 \\
\hline 72.9 & 0.299 & 88.93 & 53.4 & 73.3 & 3.01 & 77.58 & 4.54 & 73.5 & 3.83 & 71.96 & 3.07 \\
\hline 74 & 0.27 & 88.94 & 54.1 & 74.3 & 2.7 & 78.16 & 4.77 & 74.6 & 3.44 & 72.39 & 3.15 \\
\hline 75 & 0.243 & 88.94 & 54.2 & 75.4 & 2.42 & 78.67 & 4.99 & 75.6 & 3.14 & 72.85 & 3.24 \\
\hline 76 & 0.218 & 88.95 & 54.6 & 76.5 & 2.17 & 79.20 & 5.24 & 76.5 & 2.86 & 73.19 & 3.31 \\
\hline 77.1 & 0.197 & 88.96 & 55.2 & 77.5 & 1.96 & 79.64 & 5.47 & 77.5 & 2.61 & 73.52 & 3.38 \\
\hline 78.2 & 0.178 & 88.97 & 55.6 & 78.6 & 1.77 & 80.08 & 5.72 & 78.5 & 2.37 & 73.88 & 3.46 \\
\hline 79.2 & 0.143 & 88.98 & 56.1 & 79.6 & 1.59 & 80.49 & 5.97 & 79.5 & 2.18 & 74.18 & 3.53 \\
\hline
\end{tabular}



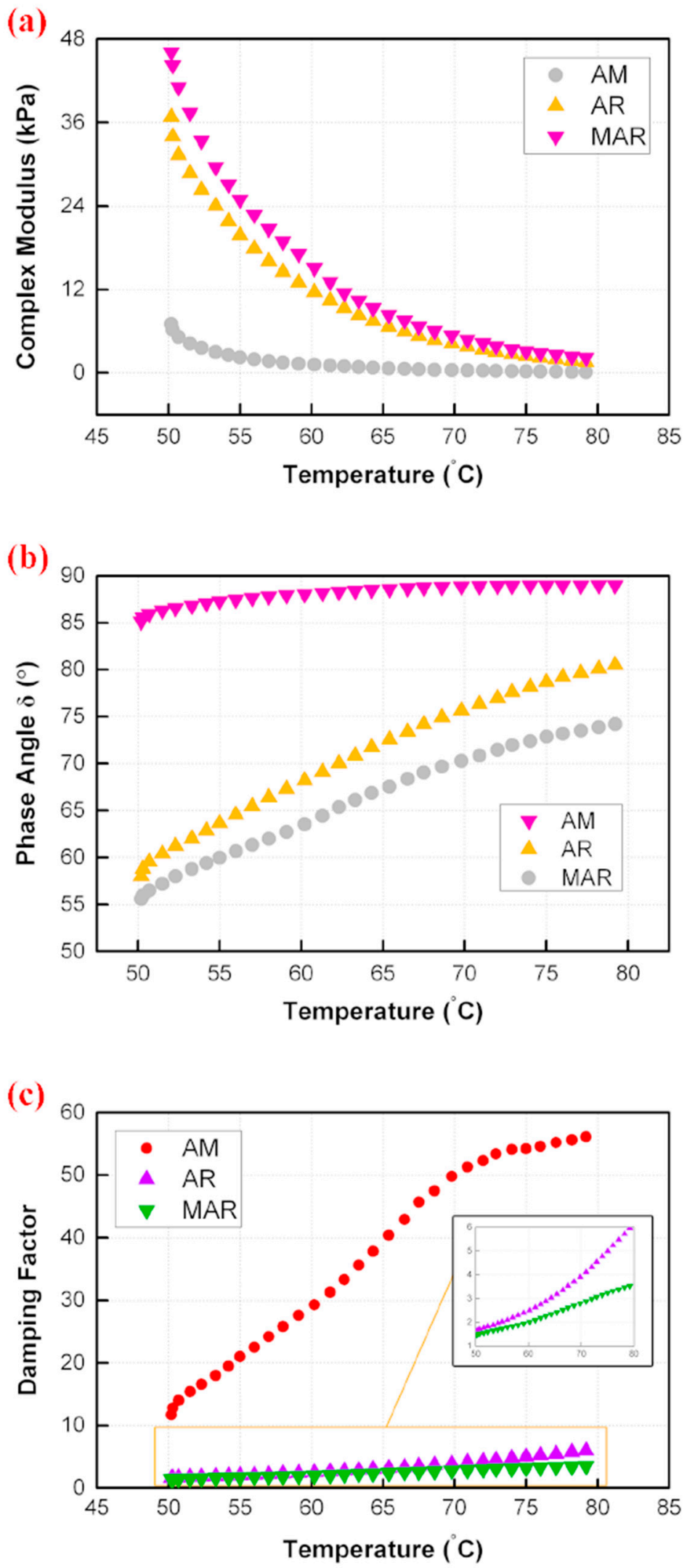

Figure 1. DSR temperature scanning test results, where (a) shows complex modulus, and (b) shows phase angle, and (c) shows damping factor. 
Figure 1a shows clearly that the complex moduli of AR and MAR were higher than those of AM with increasing temperature, and AM had the lowest complex modulus and both AR and MAR had a higher complex modulus with a similar declining trend. Because CR and MCR absorb most lightweight components, such as oil and resin, within asphalt during the rubber swelling process, the relative content of heavy components, like asphaltene, increases. In addition, due to organic functional groups of the silane coupling agent grafting on the rubber surface, MCR could absorb more oil and resin, which results in a higher complex modulus [20]. Under these circumstances, since a stronger interface has been formed between MCR and asphalt, adhesion and bonding state are enhanced as a result of the chemical effects [9] and asphalt still has a higher consistency and a better ability to resist deformation. Therefore, the ability of MAR to resist repeated shearing stress is enhanced by KH-550. However, the complex moduli of all samples decreased with increasing temperature, which means anti-shearing stress ability was gradually weakening.

Figure $1 \mathrm{~b}$ shows the change in the phase angle of the asphalt sample with temperature. It is obvious that AM had the largest phase angle while MAR had the lowest phase angle. When the phase angle was converted to tan $(\delta)$, this change in viscoelastic part within asphalt was more violent and moderate for AM and rubberized asphalt. Figure 1c shows the damping factor changing trends of AM, AR, and MAR. The tan $(\delta)$ of AM rapidly rose with increasing temperature and it reached near 60 at $80^{\circ} \mathrm{C}$. Because the non-Newtonian fluid characteristic of asphalt begins to appear with increasing temperature, at this point, the plasticity of asphalt increases and permanent deformation would occur [21]. However, AR and MAR had a similar increasing trend of $\tan (\delta)$, and $\tan (\delta)$ was significantly lower than AM. This is because of the elastomer effect of rubber, which gives asphalt a better ability to recover from deformation and significantly reduces the tan $(\delta)$ of asphalt. In addition, when the test temperature was higher than $70{ }^{\circ} \mathrm{C}$, the tan $(\delta)$ of MAR exhibited a downward trend and differences between AR and MAR increased. MCR was more stable and continuously swelled within asphalt and chemical bonds between MCR and asphalt were accrued through the polar groups of silane coupling agent, which means MCR acts as a better elastomer with a good compatibility with asphalt. As a result of the $\mathrm{KH}-550$ modification, the increasing trend of asphalt plasticity was mitigated or stopped, which prevented permanent deformation and enhancing the mechanical behavior.

Rutting factor $G^{*} / \sin (\delta)$ reflects the ability of asphalt to resist the shearing deformation at high temperatures. American Strategic Highway Research Program (SHRP) points out that if this index of asphalt is lower than $1 \mathrm{kPa}$ with increasing temperature, the test is finished and the specimen is failed [22]. According to the results of DSR temperature scanning tests, the $G^{*} / \sin (\delta)$ of AM, AR, and MAR at $58^{\circ} \mathrm{C}, 64^{\circ} \mathrm{C}, 70^{\circ} \mathrm{C}$, and $76^{\circ} \mathrm{C}$ were calculated and are presented in Figure 2 and Table 5 .

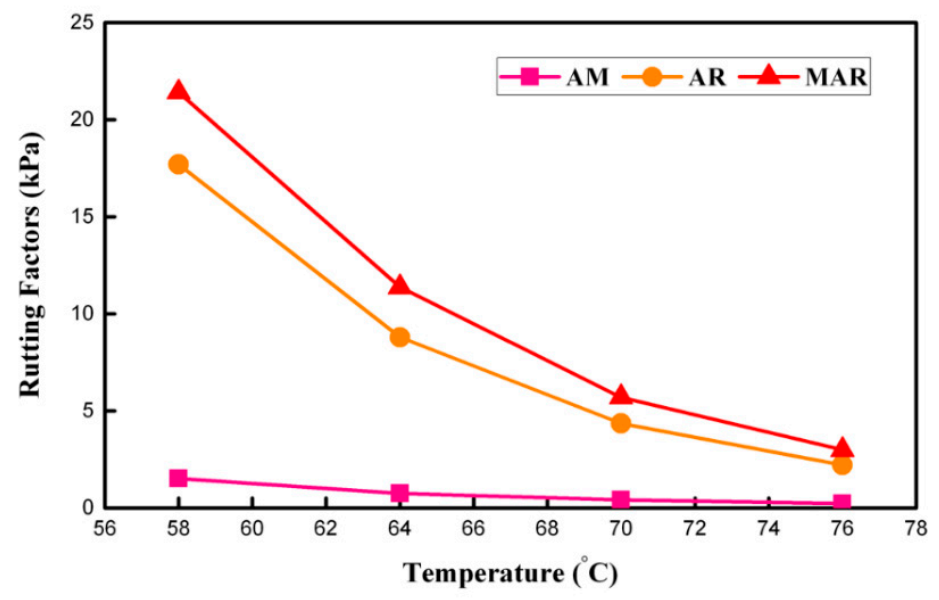

Figure 2. $G^{*} / \sin (\delta)$ of $A M, A R$, and MAR. 
Table 5. $G^{*} / \sin (\delta)$ of AM, AR, and MAR.

\begin{tabular}{cccc}
\hline \multirow{2}{*}{ Temperature $\left[{ }^{\circ} \mathrm{C}\right]$} & \multicolumn{3}{c}{$G^{*} / \sin (\delta)[\mathbf{k P a}]$} \\
\cline { 2 - 4 } & AM & AR & MAR \\
\hline 58 & 1.51 & 17.7 & 21.41 \\
64 & 0.75 & 8.79 & 11.37 \\
70 & 0.41 & 4.36 & 5.7 \\
76 & 0.22 & 2.21 & 2.99 \\
\hline
\end{tabular}

It can be seen that Figure 2 displays a similar decline trend of $G^{*} / \sin (\delta)$ for AM, AR, and MAR with increasing temperature, which presents a sensitivity of temperature. When the temperature had not yet reached $64^{\circ} \mathrm{C}$, the DSR tests of all AM samples had failed, while the $G^{*} / \sin (\delta)$ of AR and MAR samples were still $2.21 \mathrm{kPa}$ and $2.99 \mathrm{kPa}$ at a high temperature, respectively. In addition, the $G^{*} / \sin (\delta)$ of MAR samples were always higher than those of AR, which increased by $35.4 \%$ at $58{ }^{\circ} \mathrm{C}, 29.7 \%$ at $64{ }^{\circ} \mathrm{C}, 30.7 \%$ at $70{ }^{\circ} \mathrm{C}$, and $35.3 \%$ at $76{ }^{\circ} \mathrm{C}$. Because a more stable and stronger continuing integrity was formed between MCR and asphalt [9], even if the test temperature rose, the ability of MAR to transmit force, redistribute internal stress, and resist shearing deformation was much better.

Through the above analysis of the DSR temperature scanning test, it can be determined that MCR helped to raise and reduce complex modulus $S$ and damping factor $\tan (\delta)$ of asphalt under high temperature conditions. The servicing performance under a high temperature environment was improved by a stronger interface adhesion state formed between MCR and asphalt through chemical reactions, which means the dynamic mechanical properties of rubberized asphalt are enhanced by KH-550.

\subsection{Low Temperature Performance}

The mechanical and deformation behavior of asphalt at low temperature is closely related to its composition. Without any modified materials, matrix asphalt often shows more deflection and brittleness, while rubber powder can greatly improve this situation [23]. The BBR test results are shown in Table 6.

Table 6. BBR tests results.

\begin{tabular}{ccccc}
\hline Index & Temperature $\left({ }^{\circ} \mathbf{C}\right)$ & AM & AR & MAR \\
\hline \multirow{2}{*}{$S(\mathrm{MPa})$} & -24 & 683.5 & 352.7 & 306.2 \\
& -12 & 126.5 & 98.4 & 91.1 \\
\hline \multirow{2}{*}{$m(-)$} & -24 & 0.239 & 0.306 & 0.32 \\
& -12 & 0.347 & 0.412 & 0.454 \\
\hline
\end{tabular}

According to Table 6, the low temperature performance of AM was worse than that of rubberized asphalt. When the test temperature was $-12{ }^{\circ} \mathrm{C}$, the $S$ and $m$-values of $\mathrm{AM}$ were 126.5 and 0.347, respectively. At this time, the $S$ of AR and MAR was 98.4 and 91.1, respectively, while the $m$-value of AR was $18.7 \%$ higher than that of AM, and the $m$-value of MAR was $30.8 \%$ and $10.2 \%$ higher than that of AM and AR, respectively. The above results indicate that rubber powder improved the low temperature performance of asphalt, produced less low temperature deflection deformation, and enhanced the abilities of stress transmission and internal stress dissipation of rubber asphalt, however, MCR had a better improvement effect. According to Chinese specifications, $S$ should not exceed $300 \mathrm{MPa}$ and $m$-value should not be less than 0.3 . It can be seen from the table that when the temperature continued to drop to $-24^{\circ} \mathrm{C}$, the low temperature performance of asphalt sample further declined, and the $S$ of AM sharply rose to 683.5, which is $123 \%$ higher than MAR. Although the $S$ of AR and MAR were both higher than $300 \mathrm{MPa}$, their low temperature performances were obviously better than that of AM. Meanwhile, the $m$-value of AM was lower than 0.3, and its ability to dissipate 
internal stress was significantly reduced, while rubber asphalt was still higher than 0.3 , and MCR gave asphalt a better stress and force transfer effect at a lower temperature.

The main reasons for this can be concluded as follows. Under the same load level, AM tends to transform the stress into larger bending deformation due to the insufficient level of stress dissipation, and its surface is prone to cracking and brittle fracture. The addition of rubber powder improves the mechanical and force transfer behavior of asphalt. Most of the load is absorbed by rubber powder, so its $S$ is smaller and $m$-value is larger [24]. At the same time and a lower temperature, due to the better combination of MCR and asphalt caused by chemical action, on the one hand, the movement of the asphalt molecular chain is relatively reduced, on the other hand, the friction between MCR and asphalt is enhanced, which builds a better dissipation of the internal stress state. Therefore, MAR has a better low temperature performance.

\subsection{Specific Surface Area of Rubber Powder}

The combination of rubber powder and asphalt is mainly physical function. When silane coupling agent is introduced into the surface of rubber powder, the rubber powder is chemically combined with asphalt through the silane film attached to the surface of rubber powder. In order to further analyze the influence of silane coupling agent on the surface properties of rubber powder, and further explain the reasons of DSR and BBR test results, in this paper, the BET test of rubber powder was carried out to determine the effect of silane coupling agent on the specific surface area of rubber powder. The BET test results are shown in Figure 3.

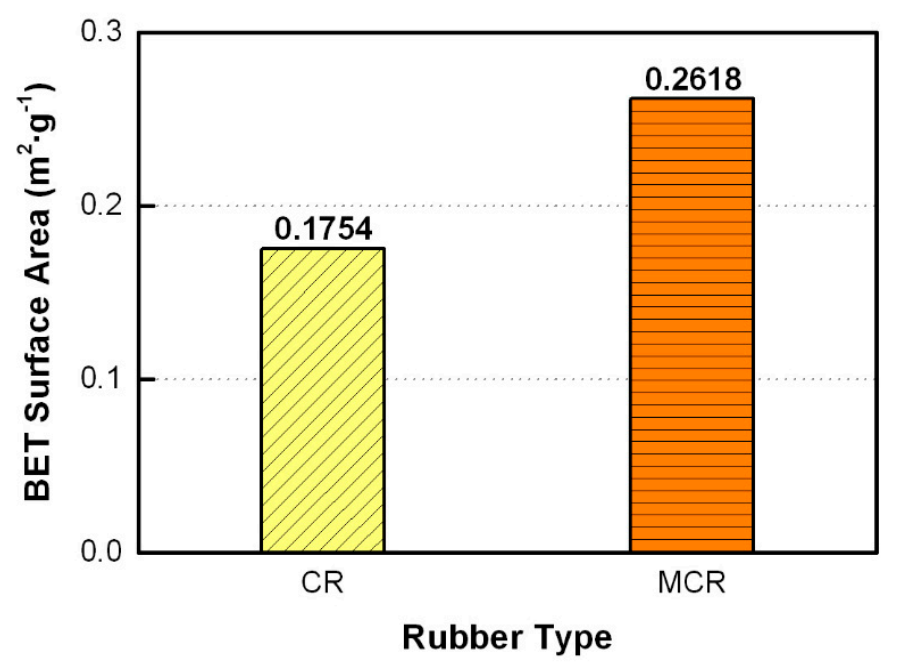

Figure 3. BET test results of normal rubber and modified rubber.

Figure 3 shows that the specific surface area of CR was $0.1754 \mathrm{~m}^{2} \cdot \mathrm{g}^{-1}$ and that area of MCR rose to $0.2618 \mathrm{~m}^{2} \cdot \mathrm{g}^{-1}$, which is $49.3 \%$ higher than CR after surface modification by silane coupling agent. Some studies have shown that the modification mechanism of silane coupling agent is to chemically attach a layer of silane film on the surface of modified material. The size, thickness, and shape of the silane film are different [25]. It can be seen that the specific surface area of MCR increased significantly because of the successful grafting of silane coupling agent molecules on its surface, which would change the surface properties of some modified materials or "add" some required functions.

MCR, due to its larger specific surface area, firstly, absorbs more oil and resin within asphalt, which further raises the relative content of asphaltene and improves the ability to resist shearing stress; then, it facilitates the formation of stable chemical bonds between MCR and asphalt, which plays the role of elastomer to better improve mechanical properties at high temperatures; lastly, it still heightens frication action between MCR and asphalt, which helps to dissipate asphalt internal stress better. 
MCR swells well and "suspends" within asphalt through chemical interactions, therefore, mechanical characteristics of MAR are further enhanced, which results in a better performance at high and low temperature environments.

\subsection{Functional Group and Chemical Bond of Asphalt}

After understanding the influence of silane coupling agent on rubber powder, the mechanism of modified rubber powder on asphalt could be further analyzed. In this paper, the change in the functional group and chemical bond of asphalt caused by the silane coupling agent was revealed by the FTIR test, and the reason why the silane coupling agent enhances the rheological properties of asphalt at high and low temperatures was further explained. The FTIR test results are displayed in Table 7 and Figure 4.

Table 7. Fourier transform infrared spectroscopy (FTIR) test results.

\begin{tabular}{|c|c|c|c|}
\hline \multirow{2}{*}{ Functional Group and Chemical Bond } & \multicolumn{3}{|c|}{ Absorption Peak Position ( $\left.\mathrm{cm}^{-1}\right)$} \\
\hline & AM & AR & MAR \\
\hline Saturated $\mathrm{C}-\mathrm{H}$ & 2923.34 and 2853.12 & 2923.48 and 2853.24 & 2923.63 and 2853.33 \\
\hline $\mathrm{C} \equiv \mathrm{C}$ & 1 & 1 & 2385.90 and 2316.52 \\
\hline $\mathrm{C}=\mathrm{C}$ & 1598.23 & 1599.17 & 1598.41 \\
\hline Methylene C-H & 1459.14 and 1375.29 & 1457.48 and 1374.81 & 1457.66 and 1374.83 \\
\hline
\end{tabular}

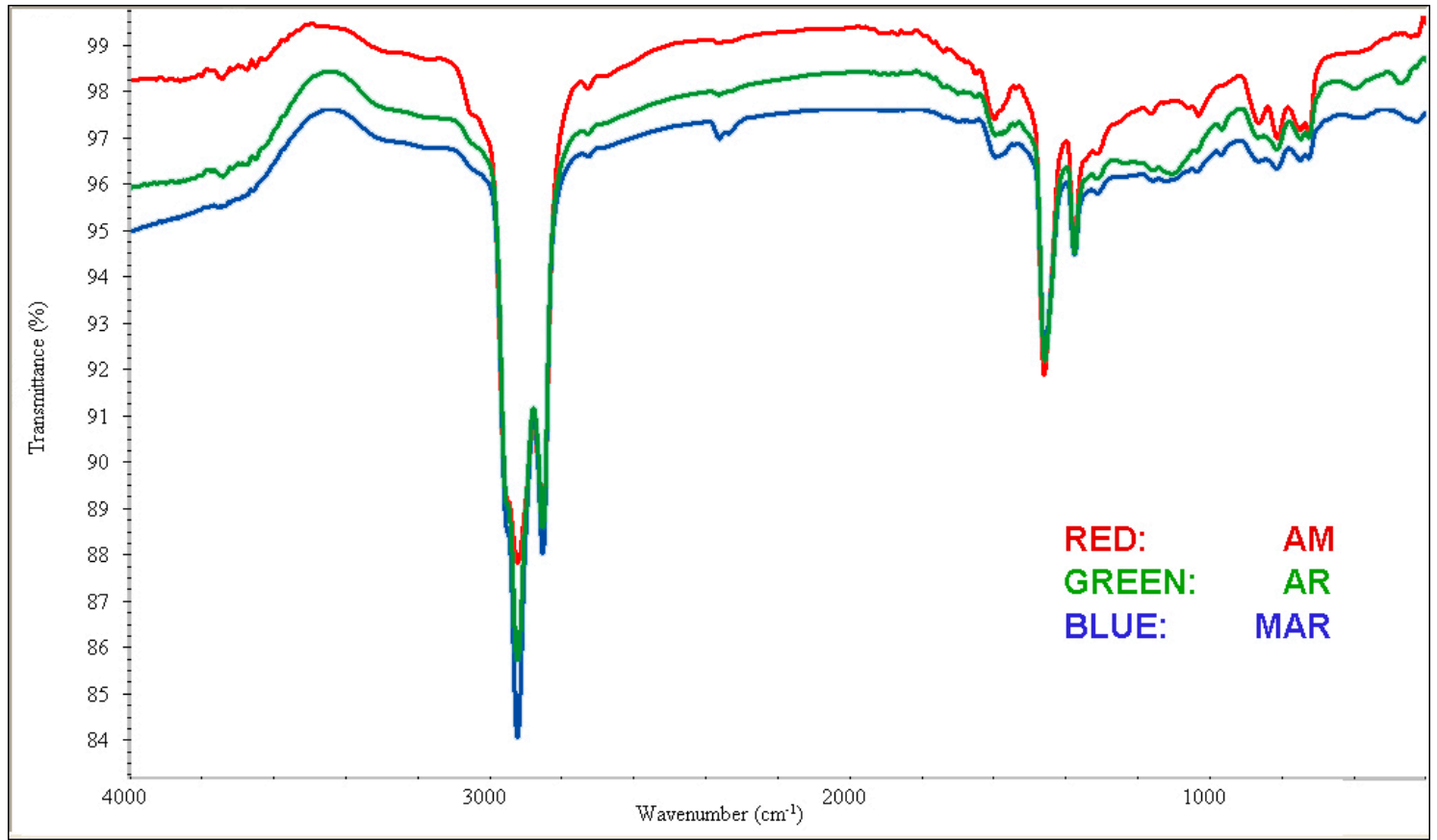

Figure 4. FTIR test result of AM, AR, and MAR.

It can be seen from Figure 4 and Table 7 that the silane coupling agent had little effect on the functional groups and chemical bonds of asphalt, but had a significant effect on the absorption of individual peaks. The absorption peaks of the $\mathrm{C}=\mathrm{C}$ bond, methylene $\mathrm{C}-\mathrm{H}$, and some fingerprint area wavenumbers of AR and MAR were weakened, which indicates that the relative contents of oil and resin declined, while the relative content of heavy components like asphaltene rose. The formation of $\mathrm{C} \equiv \mathrm{C}$ of MAR implies MCR strongly reacts with asphalt and produces new chemical bonds [26]. In addition, because saturated $\mathrm{C}-\mathrm{H}$ is already abundant in $\mathrm{CR}$, these chemical bond absorption peaks of rubberized asphalt were higher than that of $\mathrm{AM}$; on the other hand, MCR had an enhanced absorption peak of the saturated $\mathrm{C}-\mathrm{H}$ within MAR. As a result of the addition of the $\mathrm{CR}$ and $\mathrm{MCR}$, absorption 
peaks of these functional groups and chemical bonds of asphalt changed, but the changes of MAR were greater, which means that the chemical reaction between MCR and asphalt was stronger.

\section{Conclusions}

Silane coupling agent, by changing the surface properties of rubber powder, can change the interfacial adhesion state between rubber powder and asphalt from physical action to chemical action, enhance the integration of rubber powder and asphalt, and thus improve the overall mechanical properties of the rubber powder-asphalt composite system. Silane coupling agent increases the specific surface area of rubber powder and the contact area between rubber powder and asphalt. Due to the effect of silane coupling agent, there is a chemical reaction between rubber powder and asphalt and a new chemical bond is formed. Under high temperature conditions, the elastomer characteristics of rubber powder are easier to play, the complex modulus of asphalt is increased, the damping factor is greatly reduced, and the rutting factor is increased. The high temperature performance of resisting repeated shear and recovery of deformation of asphalt are improved. In a low temperature environment, the modified rubber powder keeps the stiffness modulus of asphalt at a low level, increases $m$-value, and gives asphalt a better stress and transmission capacity, which ensures the low temperature performance of rubber asphalt. The present research provides an important reference for the population and application of CR modification in road construction.

Author Contributions: Y.Z. and Z.L. designed these experiments. Y.Z. carried out all experiments and analyzed experimental results. Z.L. provided funding and supervision and J.P. provided resources (including raw materials and some test equipments). Y.Z. wrote the manuscript with Z.L.'s assistance.

Funding: This research was funded by [the National Natural Science Foundation of China] grant number [51678078].

Conflicts of Interest: The authors declare no conflicts of interest.

\section{References}

1. Wang, X.; Fan, Z.; Li, L.; Wang, H.; Huang, M. Durability evaluation study for crumb rubber-asphalt pavement. Appl. Sci. 2019, 9, 3434. [CrossRef]

2. Loderer, C.; Partl, M.N.; Poulikakos, L.D. Effect of crumb rubber production technology on performance of modified bitumen. Constr. Build. Mater. 2018, 191, 1159-1171. [CrossRef]

3. Fan, Z.; Wang, X.; Zhang, Z.; Zhang, Y. Effects of cement-mineral filler on asphalt mixture performance under different aging procedures. Appl. Sci. 2019, 9, 3785. [CrossRef]

4. Qunshan, Y.; Shaopeng, W.; Ning, L. Investigation of the dynamic and fatigue properties of fiber-modified asphalt mixtures. Int. J. Fatigue 2009, 31, 1598-1602.

5. Venudharan, V.; Biligiri, K.P. Heuristic principles to predict the effect of crumb rubber gradation on asphalt binder rutting performance. J. Mater. Civil Eng. 2017, 29, 04017050. [CrossRef]

6. Wen, Y.; Wang, Y.; Zhao, K.; Chong, D.; Huang, W.; Hao, G.; Mo, S. The engineering, economic, and environmental performance of terminal blend rubberized asphalt binders with wax-based warm mix additives. J. Clean. Prod. 2018, 184, 985-1001. [CrossRef]

7. Navarro, F.; Partal, P.; Martínez-Boza, F.; Gallegos, C. Thermo-rheological behaviour and storage stability of ground tire rubber-modified bitumens. Fuel 2004, 83, 2041-2049. [CrossRef]

8. Liang, M.; Xin, X.; Fan, W.; Ren, S.; Shi, J.; Luo, H. Thermo-stability and aging performance of modified asphalt with crumb rubber activated by microwave and TOR. Mater. Design 2017, 127, 84-96. [CrossRef]

9. Xiang, Y.; Xie, Y.; Long, G. Effect of basalt fiber surface silane coupling agent coating on fiber-reinforced asphalt: From macro-mechanical performance to micro-interfacial mechanism. Constr. Build. Mater. 2018, 179, 107-116. [CrossRef]

10. Xie, J.; Wu, S.; Pang, L.; Lin, J.; Zhu, Z. Influence of surface treated fly ash with coupling agent on asphalt mixture moisture damage. Constr. Build. Mater. 2012, 30, 340-346. [CrossRef]

11. Min, Y.; Fang, Y.; Huang, X.; Zhu, Y.; Li, W.S.; Yuan, J.; Tan, L.G.; Wang, S.; Wu, Z. Surface modification of basalt with silane coupling agent on asphalt mixture moisture damage. Appl. Surf. Sci. 2015, 346, 497-502. [CrossRef] 
12. Xiang, Y.; Xie, Y.; Liu, Z.; Long, G. Silane coupling agent on rheological performance of basalt fiber-reinforced asphalt mucilage. Petrol. Sci. Technol. 2017, 35, 993-1000. [CrossRef]

13. Yun, S.; Song, Q.; Zhao, D.; Qian, G.; Li, X.; Li, W. Study on the inorganic-organic surface modification of potassium titanate whisker. Appl. Surf. Sci. 2012, 258, 4444-4448. [CrossRef]

14. Deák, T.; Czigány, T.; Tamás, P.; Németh, C.S. Enhancement of interfacial properties of basalt fiber reinforced nylon 6 matrix composites with silane coupling agents. Express Polym. Lett. 2010, 590-598. [CrossRef]

15. Zhang, H.; Zhu, C.; Yu, J.; Shi, C.; Zhang, D. Influence of surface modification on physical and ultraviolet aging resistance of bitumen containing inorganic nanoparticles. Constr. Build. Mater. 2015, 98, 735-740. [CrossRef]

16. Gaaz, T.; Sulong, A.; Kadhum, A.; Nassir, M.; Al-Amiery, A. Surface improvement of halloysite nanotubes. Appl. Sci. 2017, 7, 291. [CrossRef]

17. Sing, K. The use of nitrogen adsorption for the characterisation of porous materials. Colloid Surf. A 2001, 187-188, 3-9. [CrossRef]

18. Zhang, L.; Xing, C.; Gao, F.; Li, T.; Tan, Y. Using DSR and MSCR tests to characterize high temperature performance of different rubber modified asphalt. Constr. Build. Mater. 2016, 127, 466-474. [CrossRef]

19. Duan, S.; Muhammad, Y.; Li, J.; Maria, S.; Meng, F.; Wei, Y.; Su, Z.; Yang, H. Enhancing effect of microalgae biodiesel incorporation on the performance of crumb Rubber/SBS modified asphalt. J. Clean. Prod. 2019, 237, 117725. [CrossRef]

20. Su, H.L.; Yang, J.; Ghataora, G.S.; Dirar, S. Surface modified used rubber tyre aggregates: Effect on recycled concrete performance. Mag. Concr. Res. 2015, 67, 680-691. [CrossRef]

21. Rekha, P.; Krishnan, J. Experimental investigations on high temperature transition of asphalt. Constr. Build. Mater. 2011, 25, 4221-4231. [CrossRef]

22. DuYChen, J.; Han, Z.; Liu, W. A review on solutions for improving rutting resistance of asphalt pavement and test methods. Constr. Build. Mater. 2018, 168, 893-905.

23. Ding, X.; Ma, T.; Zhang, W.; Zhang, D. Experimental study of stable crumb rubber asphalt and asphalt mixture. Constr. Build. Mater. 2017, 157, 975-981. [CrossRef]

24. Hajikarimi, P.; Aflaki, S.; Hoseini, A. Implementing fractional viscoelastic model to evaluate low temperature characteristics of crumb rubber and gilsonite modified asphalt binders. Constr. Build. Mater. 2013, 49, 682-687. [CrossRef]

25. Wu, D.; Liu, J.; Wang, Y. Enhancing indium tin oxide (ITO) thin film adhesiveness using the coupling agent silane. Appl. Surf. Sci. 2010, 256, 2934-2938. [CrossRef]

26. Colom, X.; Faliq, A.; Formela, K.; Canavate, J. FTIR spectroscopic and thermogravimetric characterization of ground tyre rubber devulcanized by microwave treatment. Poloym. Test. 2016, 52, 200-208. [CrossRef] 